\section{ORTHODONTIST WINS AWARD}

Joanne Collins, an FTTA in orthodontics at the Eastman Dental Institute/Kingston Hospital NHS Trust has received the British Orthodontic Society's (BOS) Chapman Prize.

Awarded annually to a BOS member for the best published article of that year, the prize is awarded to an article that contains original material on an orthodontic or allied subject.

Entitled Changes in the gender and ethnic balance of the United Kingdom orthodontic workforce, Joanne Collins' article was published in the British Dental Journal and based on research she undertook for her MSc project whilst on the MOrth training programme at the UCL Eastman Dental Institute.

The project was supervised by $\mathrm{Dr}$ Susan Cunningham, Professor Nigel Hunt, Professor John Galloway and Professor David Moles, who are co-

\section{TAXMAN TARGETS MEDICS AND DENTISTS}

Doctors and dentists are being targeted by the taxman. In a move designed to encourage them to tell HM Revenue \& Customs (HMRC) if they have understated income, medical professionals, which includes dentists, are being asked under a new Tax Health Plan to contact HMRC by 31 March 2010 to make a voluntary disclosure. After that date HMRC will carry out targeted investigations aimed at those who have not come forward and it says substantial penalties or even criminal prosecution could follow for those who have undeclared tax liabilities.

The Health Plan will operate in two stages. From 11 January to 31 March 2010, medical professionals can register their intention to make a voluntary disclosure with HMRC. By 30 June, those who have registered must have made their disclosure as well as arrangements to pay all tax interest and penalties due. Launching the campaign, Mike Wells, HMRC's Director of Risk and Intelligence said, 'The message is clear: contact us before we contact you.'

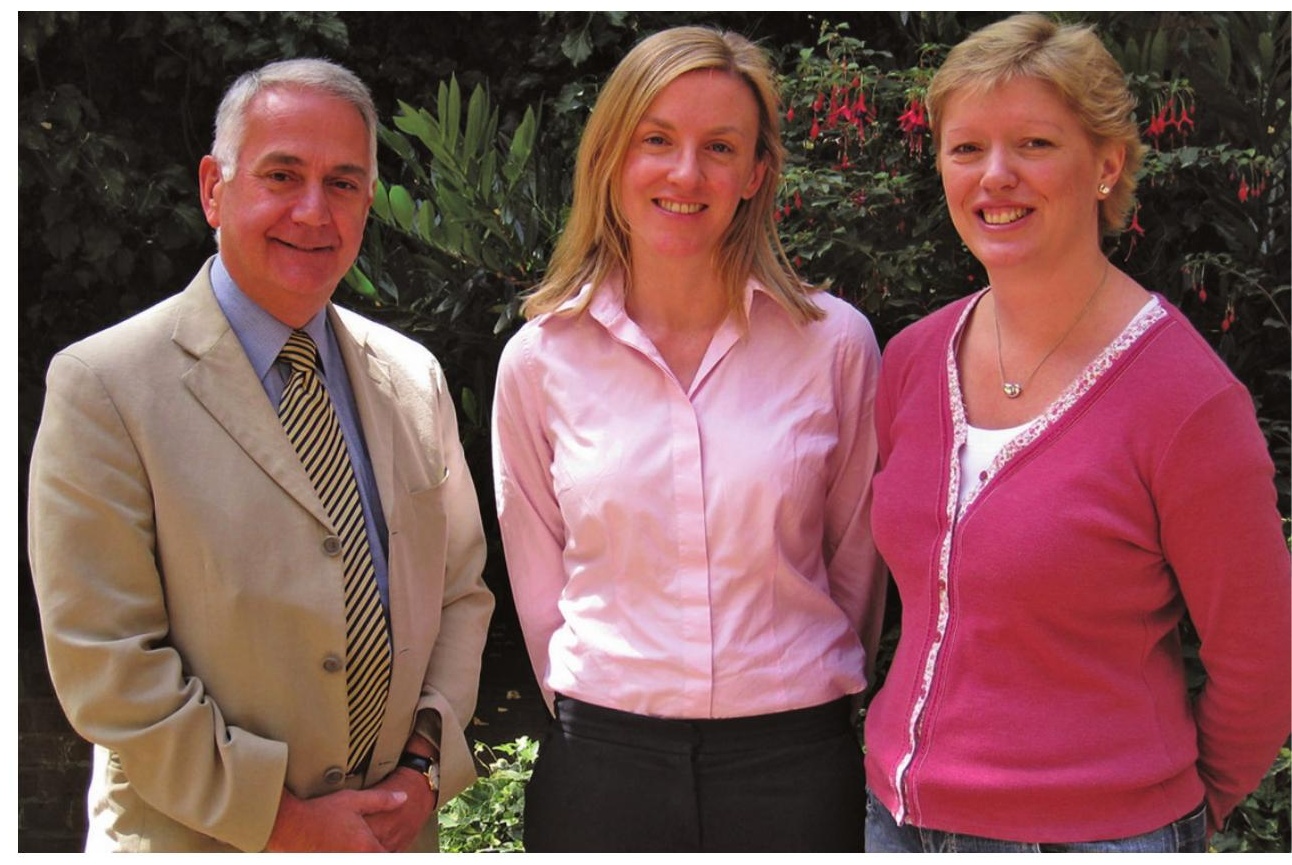

authors of the paper (Collins J M, Hunt N P, Moles D R, Galloway J, Cunningham S J. Changes in the gender and

ethnic balance of the United Kingdom orthodontic workforce. Br Dent J 2008; 205: E12).

\title{
OVERSEAS APPOINTMENT FOR UK DENTIST
}

Cosmetic dentist Doctor Ken Harris from Riveredge Cosmetic Dentistry, Low Street, Sunderland, has become a member of the John Kois Centre in Seattle after undergoing a series of exams and presentations - making him the only dentist in the UK to hold such a post.

Doctor Harris was once a student at the John Kois Centre and is now only the fifth dentist in Europe to pass the examinations. He said, 'It's a great honour as only the best graduates are invited to be teachers. As a northerner I only hope the Americans can understand me but I'm looking forward to working in both the UK and the States.'

Doctor Harris will be travelling 4,500 miles on a regular basis to teach

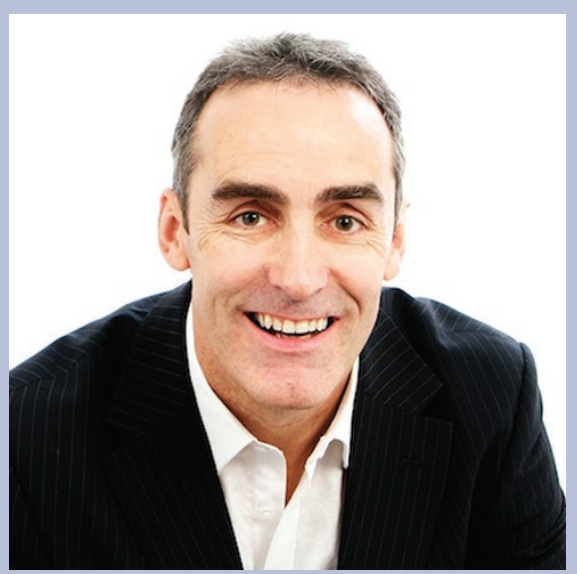

at the centre and has been asked to write up his treatment and presentation for publication in the John Kois dental journal.

\section{MORE PEOPLE PARTICIPATE IN BDJ ONLINE CPD}

Recent figures have shown that the $B D J$ online CPD programme is becoming even more popular. In 2009 there were over 78,000 visits to the site, up from 71,000 in 2008.

Currently, there are over 14,000 registered users, with approximately 6,000 log-ins per month from 3,500 individuals. The most popular location of users is the UK, followed by Australia and then the United States, but the site has been accessed from 135 countries around the world. In total, 558,000 pages have been viewed. Visit www. bdjeastmancpd.com for details. 